\title{
Fetal and Neonatal Arrhythmia in One of the Twins - a Case History
}

\author{
M. B. Czeszyńska', J. Węgrzynowski ${ }^{2}$, Z. Czajkowski ${ }^{2}$, G. Dawid ${ }^{3}$ \\ ${ }^{1}$ Clinical Department of Neonatology; ${ }^{2}$ Clinic for Pathology of Pregnancy and Labor; \\ ${ }^{3}$ Cinical Department of Child Disease.
}

\begin{abstract}
There are a lot of publications about fetal arrhythmia in singletons, but up to now there are no published data about fetal arrhythmia in multiple pregnancies. In the present study a case history of fetal and neonatal arrhythmia in one of twins from two mothers treated with betamimetic agents due to imminent preterm labor is reported and discussed. A first case with fetal bradycardia due to complete A-V block had congenital cordis abnormalities (VSD and PFO). The second case with prenatal detected extrasystoles had normal heart anatomy. Digoxin was administered to the mother, in the aim to treat fetal arrhythmia without success, because the baby had postnatal bradycardia. After hospitalisation in Cardiology Department the described cases were successfully treated. In both cases the second twins were without neonatal arrhythmia and with no structural heart abnormalities. We summarise that in situation of detection fetal arrhythmia the complexity of the problems experienced may warrant early referral to a tertiary centre where the overall management of the mother, fetus and neonate, may be undertaken.
\end{abstract}

Keywords: Twin pregnancy, Fetal arrhythmia, Newborn babies.

\section{INTRODUCTION}

Fetal heart arrhythmia is divided into 3 categories: 1 . extrasystoles; 2 . tachycardia and 3. bradycardia. In each of these fetal echocardiography follow-up is necessary during pregnancy [7]. Extrasystoles are usually evaluated every 2 weeks, they are mostly benign and no pharmacological treatment is necessary. In such situation even vaginal delivery is recommended [7]. Tachycardia should be monitored every week for any evidence of incoming fetal heart failure. In such situation pharmacological treatment is strongly recommended, usually with digoxin and digoxin with verapamil [7]. In case of bradycardia fetal echocardiography should be performed every week. Fetal heart failure usually leads to caesarean sections, similar like in cases of tachycardia [7]. 


\section{M.B. Czeszyń ska et al.}

There are a lot of publications about fetal arrhythmia in singletons [1-5], but up to now there are no published data about fetal arrhythmia in multiple pregnancies. In the present study a case history of fetal and neonatal arrhythmia in one of twins from two mothers treated with betamimetic drugs due to imminent preterm labor is reported and discussed.

\section{CASE HISTORY}

Case 1 is a 37-week-gestational age female born from III, twin pregnancy, by caesarean section with features of hypothropy as first twin; birthweight - 1250 grams and Apgar scores $-8,8,9$. Babies from previous I and II pregnancy were born as singletons with hypothropy too. The present multiple pregnancy was complicated by imminent preterm labor: since 34 week of pregnancy betamimetic agents (fenoterol) were administered as tocolityc drugs. In addition aminophylline - in the aim to treat hypotrophy of the both fetuses - were given intravenously to the mother. After a few days of tocolityc treatment fetal arrhythmia in one of the twins was detected during routine ultrasonographic examination. The diagnosis was made on the basis of pulsed Doppler flow velocimetry of fetal umbilical artery followed by fetal echocardiography. Additional suspicion of congenital fetal heart malformation was recognised. During next days betamimetics were stopped but fetal arrhytmia continued to progress.

Utrasonographical examination with fetal echocardiography was performed several times and finally bradycardia due to complete atrio-ventricul (A-V) block was diagnosed. In 37 week of pregnancy caesarean section was done due to fetal distress. After delivery bradycardia until 40 beats of heart per minutes was observed. The newborn infant was immediately placed in Cardiology Department and given a treatment with astmopent for 3 months. In the postnatal echocardiographic examination (ECHO) vitium cordis was confimed; it was ventricular septal defect and persistence foramen ovale (VSD and PFO). Bradycardia until 40/minute continues to occur during several weeks despite treatment. After 4 months of hospitalisation the baby was discharged. During a 2-year-follow-up bradycardia was not noticed and there was no evidence of heart failure.

The second twin with no fetal and neonatal arrhytmia was a female too with the same blood group and birthweight 1500 grams, Apgar scores 8, 9, 9 and with normal heart anatomy. In addition, both twins showed subclinical hypothyroidism and they were treated with L-thyroxin with success.

Case 2 is a full-term eutrophic infant born from III pregnancy by caesarean section in 38 week, with birthweight 3040 grams and Apgar scores 7, 8, 8. The maternal history revealed that first pregnancy was ended by spontaneous abortion and from second a normal full-term healthy baby was born. Imminent preterm labor (since 27 week) and gestational diabetes mellitus, treated with insulin, complicated a present twin pregnancy. Betamimetics were administered orally (fenoterol) to arrest preterm labor. After 5 weeks of tocolytic treatment with fenoterol, fetal arrhythmia in one of the twins was detected during ultrasonographical examination. Prenatal diagnosis of extrasystoles was made by pulsed Doppler flow velocimetry of fetal umbilical artery followed by ECHO. Heart anatomy was normal. In 32 week of pregnancy antiarrhythmic agents, digoxin, in the aim to treat fetal arrhythmia was administered orally in dosis of $0,5 \mathrm{mg}$ per day to the mothers. In 33 week, 
for a short time, fetal extrasystoles were noticed not only in the first but in both twins. Then, after a few days, only the first fetus was still arrhythmic. Treatment with digoxin was kept without success until operative delivery, made due to deterioration of the arrhythmic fetus condition. Postnatal bradycardia, until 40/minutes, was observed in the first twin and baby was immediately placed in Cardiology Department. Bradycardia was noticed during the first 3 days after delivery and next stopped spontaneously without treatment. Normal heart rhythm was observed until 14th day of life and baby was discharged in a good condition. During 2-years follow-up no abnormalities have been noticed.

The second twin-male too with same blood group, birthweight 3140 grams, Apgar scores $8,8,8-$ had normal heart anatomy similar to the first twin but no neonatal arrhythmia.

\section{DISCUSSION}

Betamimetics are widely used as pharmacologic agents to arrest preterm labor. On the other hand all of the betamimetic drugs have been associated with side effects [8]. These have included maternal tachycardia, hypotension, chest tightness, S-T depression on ECG, pulmonary edema, myocardial ischemia, hyperglycemia, hyperinsulinemia and hypokaliemia as well as lactic and ketoacidosis have been reported during betamimetic administration [8]. Such therapy of imminent preterm labor is not contraindicated in patients with overt diabetes, however patients should be carefully monitored to avoid ketoacidosis and fetal demise [8].

In the cases which we described fetal extrasystole and bradycardia occurred during betamimetic treatment of the mothers; however it seems that such arrhythmia is probably not connected with prenatal exposure to betamimetic agents.

Fetal arrhythmia was detected by pulsed Doppler flow velocimetry of fetal umbilical artery and confirmed by ECHO. Others authors detected fetal arrhythmia by external cardiotocography [6] during routine prenatal care of pregnant women, by pulsed Doppler velocimetry of the fetal abdominal aorta and inferior vena cava [1] and next more fully diagnosed by fetal ECHO.

Very interesting is that neonatal arrhythmia was observed only in one of the twins; in case 1 it was connected with abnormal heart anatomy, but in case 2 both twins had structurally normal heart. Furthermore in both cases twins were probably monozygotic (the same sex and blood group different from maternal).

Fetal arrhythmia is often connected with abnormal heart anatomy. In one of two cases of fetal arrhythmia congenital heart malformations (VSD and PFO) were postnatally confirmed. In the reported cases bradycardia due to complete A-V block was connected with vitium cordis. So in all cases of prenatal arrhythmia and especially in bradycardia prenatal ECHO examination should be done.

In case 1 after 3 months of treatment with astmopent and 1 -thyroxin brady-arrhythmia due to A-V block progressively disappeared and now baby is doing well despite of VSD. Engelhardt [3] reported that the outcome of the fetus with congenital complete A-V block depends upon the degree of bradycardia and association with congenital heart abnormalities. 


\section{M.B. Czeszyńska et al.}

Observations which were made in case 2 may lead to the conclusion that neonatal bradycardia may be caused by prenatal persistent exposure to digoxin given to the mothers. So treatment with digoxin in cases of extrasystoles should be given carefully and under monitoring of digoxin concentration not only in maternal but also in fetal blood. Respondek [7] describes that pharmacological treatment of fetal extrasystoles is even not necessary.

Summarising, we agree with Rajadurai's and Menahem's opinion [5] according to which the diagnosis, careful assessment and management of the fetal arrhythmia may lead to successful outcome. In situation of detection of fetal arrhythmia the complexity of the problems experienced may warrant early referral to a tertiary centre where the overall management of the mother, fetus and neonate, may be undertaken.

\section{REFERENCES}

1. Chan FY, Woo SK, Ghosh A, Tang M, Lam C (1990): Prenatal diagnosis of congenital fetal arrhythmias by simultaneous pulsed Doppler velocimetry of the fetal abdominal aorta and inferior vena cava. Obstet Gynecol 76: 200-205.

2. Chorro FJ, Santonja J, Merino J, Losada A, Sanchis J, Lopez-Merino V (1992): Fetal cardiac arrhythmia characterized by Doppler echocardiography. Rev Esp Cardiol 45: 215-218.

3. Engelhardt W, Lehnen H, Grabitz R, von Bernuth G (1990): Diagnosis and therapy of fetal brady-arrhythmia. Z Geburtshilfe Perinatol 194, 153-157.

4. Maragnes P, Fournier A, Lessard M, Fouron JC (1991): Evaluation and prognosis of fetal arrhythmia. Pediatrie Bucur 46: 481-488.

5. Rajadurai FS, Menahem S (1992): Fetal arrhythmia: a 3-years experience. Aust N Z J Obstet Gynaecol 32: 28-31.

6. Respondek M, Huhta JC, Wood D, Respondek M (1990): Echocardiographic evaluation of fetal arrhythmias. Kardiol Pol 33: 136-149.

7. Respondek M, Wilczyński J (1994): Clinical follow-up in a case of fetal arrhythmia - review of the literature. Ginekol Pol 65: 714-718.

8. Veille J-C (1992): Obstetric management of prematurity. In: Neonatal-Perinatal Medicine, Fanaroff A, Martin R (ed), Mosby Year Book 205-220.

Correspondence: Maria Beata Czeszyńska, Department of Neonatology, ul. Unii Lubelskiej 1, 71-252 Szczecin. 